IOS Press

\title{
Review
}

\section{Connecting Cohorts to Diminish Alzheimer's Disease (CONCORD-AD): A Report of an International Research Collaboration Network}

Valory N. Pavlik ${ }^{\mathrm{a}, *}$, Samantha C. Burnham ${ }^{\mathrm{b}}$, Joseph S. Kass ${ }^{\mathrm{a}}$, Catherine Helmer ${ }^{\mathrm{c}}$, Sebastian Palmqvist ${ }^{\mathrm{d}, \mathrm{g}}$, Maria Vassilakie ${ }^{\mathrm{e}}$, Jean-François Dartigues ${ }^{\mathrm{c}, \mathrm{f}}$, Oskar Hansson ${ }^{\mathrm{d}, \mathrm{g}}$, Colin L. Masters ${ }^{\mathrm{h}}$, Karine Pérès ${ }^{\mathrm{c}}$, Ronald C. Petersen ${ }^{\mathrm{e}, \mathrm{i}}$, Erik Stomrud ${ }^{\mathrm{d}, \mathrm{g}}$, Lesley Butler $^{\mathrm{j}}$, Preciosa M. Coloma ${ }^{\mathrm{j}}$, Xavier M. Teitsma ${ }^{\mathrm{j}}$, Rachelle Doody ${ }^{\mathrm{k}, \mathrm{l}}$ and Mary Sano ${ }^{\mathrm{m}, \mathrm{n}}$ for the CONCORD-AD investigators

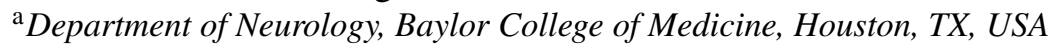

${ }^{\mathrm{b}}$ The Australian eHealth Research Centre, CSIRO Health and Biosecurity, Melbourne, VIC, Australia

${ }^{\mathrm{c}}$ University of Bordeaux, Inserm, Bordeaux Population Health Research Center, UMR, Bordeaux, France

${ }^{\mathrm{d}}$ Clinical Memory Research Unit, Lund University, Lund, Sweden

${ }^{\mathrm{e}}$ Department of Quantitative Health Sciences, Division of Epidemiology, Mayo Clinic, Rochester, MN, USA

${ }^{\mathrm{f}}$ Department of Neurology, Memory Consultation, Bordeaux University Hospital, Bordeaux, France

${ }^{\mathrm{g}}$ Memory Clinic, Skåne University Hospital, Malmö, Sweden

${ }^{\mathrm{h}}$ The Florey Institute and The University of Melbourne, Parkville, VIC, Australia

i Department of Neurology, Mayo Clinic, Rochester, MN, USA

j Product Development Personalised Health Care - Data Science, F. Hoffmann-La Roche Ltd, Basel, Switzerland

${ }^{\mathrm{k}}$ Product Development Neuroscience, F. Hoffmann-La Roche Ltd, Basel, Switzerland

${ }^{1}$ Product Development Neuroscience, Genentech, Inc., South San Francisco, CA, USA

${ }^{\mathrm{m}}$ Department of Psychiatry, Alzheimer's Disease Research Center, Icahn School of Medicine at Mount Sinai, New York, NY, USA

${ }^{\mathrm{n}}$ James J. Peters VA Medical Center, Bronx, NY, USA

Accepted 14 October 2021

Pre-press 8 November 2021

\begin{abstract}
Longitudinal observational cohort studies are being conducted worldwide to understand cognition, biomarkers, and the health of the aging population better. Cross-cohort comparisons and networks of registries in Alzheimer's disease (AD) foster scientific exchange, generate insights, and contribute to the evolving clinical science in AD. A scientific working group was convened with invited investigators from established cohort studies in $\mathrm{AD}$, in order to form a research collaboration network as a resource to address important research questions. The Connecting Cohorts to Diminish Alzheimer's Disease (CONCORD-AD) collaboration network was created to bring together global resources and expertise, to generate insights and improve understanding of the natural history of $\mathrm{AD}$, to inform design of clinical trials in all disease stages, and to plan
\end{abstract}

\footnotetext{
${ }^{*}$ Correspondence to: Valory Pavlik, PhD, Department of Neurology, Baylor College of Medicine, 7200 Cambridge St., 9th
}

Floor, Houston, TX 77030, USA. Tel.: +1 713798 7444; Fax: +1 713798 7434; E-mail: vpavlik@bcm.edu. 
for optimal patient access to disease-modifying therapies once they become available. The network brings together expertise and data insights from 7 cohorts across Australia, Europe, and North America. Notably, the network includes populations recruited through memory clinics as well as population-based cohorts, representing observations from individuals across the AD spectrum. This report aims to introduce the CONCORD-AD network, providing an overview of the cohorts involved, reporting the common assessments used, and describing the key characteristics of the cohort populations. Cohort study designs and baseline population characteristics are compared, and available cognitive, functional, and neuropsychiatric symptom data, as well as the frequency of biomarker assessments, are summarized. Finally, the challenges and opportunities of cross-cohort studies in $\mathrm{AD}$ are discussed.

Keywords: Alzheimer's disease, biomarkers, cognitive function, cohort, CONCORD-AD network, dementia, observational study, population characteristics

\section{BACKGROUND}

Alzheimer's disease (AD) is the leading cause of dementia [1]. It is a progressive and, as of yet, incurable neurodegenerative disease that has devastating consequences for the lives of affected individuals and their families. Fifty million people worldwide were living with dementia in 2018 , and this number is expected to more than triple to reach 152 million by 2050 [2]. Dementia is a leading cause of morbidity, mortality, and disability, especially among the elderly [3]. Economic estimates have suggested the total annual cost of dementia worldwide was approximately 1 trillion US dollars in 2018, and this cost is expected to double by 2030 [2]. Without intervention, AD will devastate public health resources and overwhelm the current healthcare infrastructure on a global scale. Postponing dementia onset by even just one year could result in nine million fewer cases worldwide than predicted for 2050 [4].

To mitigate the impact of AD on both the individual and society, novel disease-modifying therapies are urgently needed to treat the disease or delay its onset. The development of new therapies must also be accompanied by careful analysis of the populations most affected by $\mathrm{AD}$ and the potential impact of new treatment options on clinical practice. To this end, a variety of longitudinal observational studies are being conducted around the world to assess cognition, biomarkers, and the health of the aging population. These range from populationbased community studies monitoring participants with and without dementia at enrollment, to studies of older adults from memory clinics with complaints of cognitive decline. International collaborations that leverage diverse clinical data and scientific expertise could improve our understanding of disease etiology and the natural history of $\mathrm{AD}$, generate insights to inform the design of preventive and therapeutic trials, and inform health-service planning for optimal early detection of cognitive decline and patient access to new disease-modifying therapies as they become available.

Cross-cohort analyses and networks of registries in $\mathrm{AD}$ have previously been established, each with its own objectives, e.g., to facilitate clinical trial recruitment [5], monitor changes in the incidence of dementia [6, 7], identify risk factors, improve early diagnosis, or address specific research questions [8-10]. In addition, publicly available collaborative resources such as the Global Alzheimer's Association Interactive Network (GAAIN) research platform [11] have been set up to allow researchers to access data being collected across the globe and to promote consistency and comparability across cohort analyses. The newly assembled Connecting Cohorts to Diminish Alzheimer's Disease (CONCORD-AD) network was created to foster scientific exchange, generate insights, and contribute to the evolving clinical science in $\mathrm{AD}$.

\section{DEVELOPMENT OF THE INTERNATIONAL CONCORD-AD COLLABORATION NETWORK}

In August 2016, a group of investigators from around the world, representing observational prospective cohorts of individuals across the AD continuum, convened to form a scientific working group; its aim, to establish a research collaboration network as a resource to address important research questions related to the natural history and burden of AD. A group of investigators from established longitudinal cohort studies in $\mathrm{AD}$ were invited to 
Table 1

Study and baseline characteristics of the cohorts included in the CONCORD-AD network at study enrollment

\begin{tabular}{|c|c|c|c|c|c|c|c|}
\hline & AIBL & Baylor & BioFINDER-1 & MCSA & PAQUID & 3C Bordeaux & AMI \\
\hline \multicolumn{8}{|l|}{$\overline{\text { Study participants }}{ }^{\mathrm{a}}, n(\%)$} \\
\hline $\mathrm{CU}$ & $1,190(66)$ & $76(3)$ & $834(68)$ & $4,055(86)$ & $3,575^{\mathrm{b}}(98)$ & $2,027^{\mathrm{b}}(97)$ & $877^{\mathrm{b}}(91)$ \\
\hline MCI & $295(16)$ & $413(13)$ & $292(24)$ & $562(12)$ & N/A & N/A & N/A \\
\hline $\mathrm{AD}$ & $322(18)$ & $2,622(84)$ & $93(8)$ & $79^{\mathrm{d}}(2)$ & $79(2)$ & $59(3)$ & $86^{\mathrm{e}}(9)$ \\
\hline Country & Australia & USA & Sweden & USA & France & France & France \\
\hline Setting & $\begin{array}{l}\text { Memory clinic and } \\
\text { population-based }\end{array}$ & $\begin{array}{l}\text { Memory } \\
\text { clinic }\end{array}$ & $\begin{array}{l}\text { Memory clinic and } \\
\text { population-based }\end{array}$ & $\begin{array}{l}\text { Population- } \\
\text { based }\end{array}$ & $\begin{array}{l}\text { Population- } \\
\text { based }\end{array}$ & $\begin{array}{l}\text { Population- } \\
\text { based }\end{array}$ & $\begin{array}{l}\text { Population- } \\
\text { based }\end{array}$ \\
\hline Mean follow-up $(y)^{c}$ & $\sim 4.5$ & $\sim 3$ & $\sim 5$ & $\sim 5$ & 12.0 & 12.7 & 5.5 \\
\hline Attrition rate per year $(\%)$ & 8.7 & 5.1 & 4.8 & 7.5 & 3.6 & 4.3 & 5.9 \\
\hline Ongoing follow-up (yes/no) & Yes & Yes & Yes & Yes & No & Yes & Yes \\
\hline Age $>70 \mathrm{y}, n(\%)$ & $1,001(55)$ & $2,158(68)$ & $921(59)$ & $3,326(71)$ & $2,677(71)$ & $1,636(78)$ & $786(78)$ \\
\hline Male, $n(\%)$ & $768(43)$ & $1,240(39)$ & $740(48)$ & $2,388(51)$ & $1577(42)$ & $816(39)$ & $626(62)$ \\
\hline$>12 \mathrm{y}$ of education, $n(\%)$ & $895(49)$ & $1,883(59)$ & $584(38)$ & $3,009(64)$ & $387(10)$ & $779^{f}(37)$ & $50^{\mathrm{g}}(5)$ \\
\hline$A P O E \varepsilon 4$ carrier, $n(\%)$ & $547(30)$ & $1,427(46)$ & $587(38)$ & $1,299(28)$ & $151^{\mathrm{h}}(23)$ & $365^{\mathrm{i}}(20)$ & $114^{\mathrm{j}}(18)$ \\
\hline
\end{tabular}

AD, Alzheimer's disease; AIBL, Australian Imaging, Biomarkers \& Lifestyle Flagship Study of Ageing; AMI, AGRICA-MSA-Institut fédératif de recherche en santé publique/Aging Multidisciplinary Investigation; APOE $\varepsilon 4$, apolipoprotein E $\varepsilon 4$ allele; Baylor, Alzheimer's Disease and Memory Disorders Center at Baylor College of Medicine; BioFINDER-1, Biomarkers For Identifying Neurodegenerative Disorders Early and Reliably; CU, cognitively unimpaired; MCI, mild cognitive impairment; MCSA, Mayo Clinic Study of Aging; PAQUID, Personnes Agées QUID; 3C Bordeaux, Three-City Study. ${ }^{a}$ Selected cohorts also enrolled participants with other types of dementia (not displayed in the present report); ${ }^{\mathrm{b}}$ Non-demented; ${ }^{\mathrm{c}}$ Mean follow-up period at the time individual cohort data were submitted for inclusion within the CONCORD-AD analyses; ${ }^{\mathrm{d}} \mathrm{AD}$ or other dementia; ${ }^{\mathrm{e}} \mathrm{AD}$ or AD plus another form of dementia; ${ }^{\mathrm{f}}$ Data available for 2,099 participants; ${ }^{g}$ Data available for 999 participants; ${ }^{h}$ Data available for 646 participants; ${ }^{i}$ Data available for 1,866 participants; ${ }^{j}$ Data available for 647 participants.

participate, representing a diverse range of studies from around the globe. The resultant CONCORD$\mathrm{AD}$ network brought together expertise and data insights from seven cohorts across Australia, Europe, and North America. Notably, the network includes populations recruited through memory clinics and population-based cohorts, bringing together observations from individuals across the $\mathrm{AD}$ spectrumfrom cognitively unimpaired (CU) people with or without subjective cognitive decline (SCD), to those with mild cognitive impairment (MCI), through to those with $\mathrm{AD}$, as well as other types of dementia. Although each cohort was established with different objectives, this network provides the opportunity to address novel research questions across the cohorts and to leverage disease area expertise among the investigators.

In this article, we introduce the CONCORD-AD network, provide an overview of the cohorts involved, report the common assessments used in the cohorts, and describe the key characteristics of the cohort populations. We show examples of knowledge gaps already being addressed by each cohort and highlight the diversity, similarities, and complementarity among these different data sources. We also provide recommendations on how such collaborations may evolve in the future, and the challenges and opportunities they can present.

\section{OVERVIEW OF THE CONCORD-AD PARTICIPATING COHORTS}

The seven cohorts participating in the CONCORDAD network represent data from more than 20,000 individuals across the disease spectrum, with a maximum follow-up period of 27 years. The key characteristics of the different cohorts are summarized in Table 1, and the definitions used for CU, MCI, or AD cognitive subgroups are listed in Supplementary Table 1 [44-53]. Brief summaries of the cohort study design and their previous applications in research follow. The required ethical approval processes were completed as appropriate within the individual studies.

\section{The Australian Imaging, Biomarker \& Lifestyle Flagship Study of Ageing (AIBL) Cohort}

The AIBL study was established in 2006 in Australia and had recruited 1,807 participants aged $\geq 60$ years at the time the CONCORD-AD network was established (CU, $n=1,190$; MCI, $n=295$; AD, $n=322$; June 1, 2018 analysis) through treating physicians at memory clinics and community appeals [12]. Assessments took place at central locations in Melbourne and Perth, depending on whether participants underwent brain imaging, and where they 
lived; a small number were also assessed at home by AIBL staff. The AIBL cohort has given rise to diverse research publications and further studies, including imaging studies exploring the relationship between aggregated amyloid- $\beta(\mathrm{A} \beta)$ and gray matter atrophy [13], studies exploring the application of new research frameworks and analytical techniques in the AIBL cohort [14-16], cognition-function studies [17], and the potential for introducing physical activity interventions in participants at risk for $\mathrm{AD}$ or with subjective memory complaints [18].

\section{The Alzheimer's Disease and Memory Disorders Center at Baylor College of Medicine (Baylor) cohort}

Since 1989, the US-based Baylor study has recruited 3,181 participants aged $\geq 60$ years $(\mathrm{CU}, n=$ 76; $\mathrm{MCI}, n=413$; $\mathrm{AD}, n=2,622$; NovemberDecember 2017 analysis) referred to the Baylor memory clinic [19]. Self-referred and physician-referred participants with memory complaints were recruited at the Houston, TX, USA clinic and underwent various laboratory tests, including neuroimaging and psychometric assessments. Previous publications based on these data have evaluated the relationship between initial progression rate and subsequent longitudinal progression of cognitive and functional measures [20], prevalence, predictors, and clinical outcomes of different cognitive profiles within $\mathrm{AD}$ [21-25], and overall survival in participants with probable AD [26].

\section{The Swedish Biomarkers for Identifying Neurodegenerative Disorders Early and Reliably (BioFINDER-1) Study}

The Swedish BioFINDER-1 study started to recruit participants in 2008 to address the knowledge gaps in early detection of underlying pathologies and subsequent disease mechanisms in AD and Parkinson's disease [27], and has recruited 1,554 participants, including 1,219 in the cohort for $\mathrm{AD}$-focused research (CU, $n=834$; MCI, $n=292 ; \mathrm{AD}, n=93$; as of March 16, 2020). Participants aged $\geq 60$ years with mild cognitive symptoms, dementia, and Parkinsonian symptoms were recruited through memory and neurology clinics at several participating centers in Sweden; healthy CU elderly participants were recruited through a pre-existing populationbased community cohort [28]. BioFINDER-1 data have been used to explore the use and accuracy of biomarkers for diagnosing $\mathrm{AD}[29,30]$ and how this could be further optimized [31-33], and also to evaluate the relationship between biomarkers and pathology [34, 35].

\section{The Mayo Clinic Study of Aging (MCSA)}

The Mayo Clinic Study of Aging (MCSA) is a prospective population-based cohort study (most participants $\geq 50$ years old) established in 2004 in Olmsted County (MN), USA, to investigate the prevalence and incidence of MCI, cognitive aging, as well as the risk factors and conversion rates for $\mathrm{MCI}$ and dementia (CU, $n=4,055$; MCI, $n=562$; dementia, $n=79$; as of February 28, 2018 analysis). MCSA examines the prevalence of cognitive impairment, dementia and vascular biomarkers [36] and their association with cognitive outcomes [37-41] as well as the development of risk scores to predict biomarker and cognitive outcomes [42].

\section{Personnes Agées QUID (PAQUID)}

The PAQUID study recruited older adults, aged $\geq 65$ years and living at home, from the general population in Southwestern France in order to study normal and pathological cerebral aging [43] (nondemented, $n=3,675$; $\mathrm{AD}, n=79$; non-AD dementia, $n=23$ per baseline assessment; based on prevalent cases at inclusion in 1988-1990; last visits: October 2015-July 2016). This study has the longest followup time of the included cohorts, established in 1988 with as much as 30 years of follow-up. PAQUID data have been used in epidemiological studies to estimate dementia and cognitive impairment prevalence and incidence trends together with the 3C Bordeaux and AMI cohorts [44, 45], to evaluate relationships between social/environmental factors and cognitive decline and dementia [46], to evaluate factors affecting healthcare resource use in participants with dementia (with 3C study and AMI cohorts) [47], and to evaluate functional and cognitive trajectories of decline before dementia and brain vulnerability [48-50].

\section{Three-City Study Bordeaux (3C Bordeaux)}

The 3C Study is a population-based, longitudinal study that started in 1999 and has a maximum followup time of 17 years. The study recruited participants aged $\geq 65$ years from the general populations of three cities in France: Bordeaux, Dijon, and Montpellier 
[51], including 2,104 participants from the Bordeaux center, data from whom are part of the CONCORD$\mathrm{AD}$ network (non-demented, $n=2,027$; $\mathrm{AD}, n=59$; non-AD dementia, $n=18$; based on prevalent cases at inclusion 1999-2001). Epidemiological studies using this cohort have evaluated the associations between depressive symptoms, co-morbidities such as diabetes, and dietary factors on the risk of dementia and AD [52-57].

The COGICARE study is an ancillary substudy of the Three-City (3C) study in Bordeaux and Montpellier centers. COGICARE was designed to characterize the natural history of cognitive and functional decline around dementia through close follow-up of subjects at three different stages: $A D$, MCI, or cognitively normal. It began at the 10 -year follow-up of the 3C study and included 467 participants who underwent cognitive and functional assessments every 6 months, for up to 24 months, in addition to their $3 \mathrm{C}$ follow-ups. The protocol of the COGICARE study was approved by the Ethics Committee of Sud-Méditerranée III (France) and written informed consent was obtained for each participant.

\section{Aging Multidisciplinary Investigation (AMI)}

The AMI study was established in 2007 to study health and aging in elderly farmers in rural areas of France [58] (maximum follow-up: 10 years). The study recruited 1,002 participants aged $\geq 65$ years from the Farmer Health Insurance rolls who had retired from agriculture (non-demented, $n=877 ; \mathrm{AD}$, $n=86$; non-AD dementia, $n=39$; based on prevalent cases at inclusion 2007-2009; last visits: April 2014-May 2015). In addition to collaborative analyses with the PAQUID and 3C Bordeaux cohorts, has allowed researchers to further investigate dementia screening in the elderly [59] and putative associations between the $\mathrm{C}-\mathrm{C}$ Motif Chemokine Ligand 11 biomarker and cognitive status in older participants [60].

\section{THE COMPLEMENTARITY AND DIVERSITY OF THE CONCORD-AD NETWORK}

\section{Patient demographics and characteristics}

As a consequence of the varied study designs, recruitment protocols, and inclusion/exclusion criteria of the different cohorts, there were differences in the demographic make-up of the participants enrolled in each of these studies (Table 1). Cohorts in CONCORD-AD include participants recruited either from memory clinics (Baylor study), the community population (MCSA, PAQUID, 3C Bordeaux, and AMI), or both memory clinics and the general population (AIBL and BioFINDER-1). The percentage of participants aged $>70$ years ranged from $55 \%$ (AIBL) to $78 \%$ (AMI and 3C Bordeaux) and the percentage of male participants varied from $39 \%$ in Baylor and $3 \mathrm{C}$ Bordeaux to $62 \%$ in AMI, where the high percentage of males in an aging population can be attributed to the inclusion criteria requiring participants to be retired from agriculture and affiliated to the Health Insurance under their own name (in some regions women were commonly affiliated under their husband's name). Educational background varied markedly, with only $5 \%$ of the AMI rural cohort completing $>12$ years of education, compared with $64 \%$ in MCSA. The prevalence of apolipoprotein E $\varepsilon 4$ allele ( $A P O E \varepsilon 4)$ carriers varied widely as well, from $18 \%$ (AMI) to $46 \%$ (Baylor) in keeping with the higher percentage of people with $\mathrm{AD}$ at the Baylor site.

Assessments available for cross-cohort comparison in CONCORD-AD

A wide variety of assessments were used to monitor cognition, function, neuropsychiatric symptoms (NPS), and biomarkers in the CONCORD-AD cohorts (Fig. 1). The most common cognitive assessment was the Mini-Mental State Examination (MMSE), which was used in all cohorts except the MCSA, which included the Short Test of Mental Status from which MMSE score can be derived [61, 62]. The Clinical Dementia Rating - Sum of Boxes (CDR-SB), a commonly used metric in clinical trials, was assessed in four of the cohorts, while the Digit Symbol Substitution Test (DSST), Isaacs Set Test (IST), and Wechsler Memory Scale-Revised (WMS-R) were each applied in three cohorts. An Activities of Daily Living (ADL) questionnaire was the most commonly used functional assessment, and three different functional assessments were used in $\geq 2$ cohorts (Fig. 1). The Lawton Instrumental ADL (IADL) scale was assessed in the Baylor and French cohorts. Similarly, three distinct inventories were used to measure neuropsychiatric symptoms in $\geq 2$ cohorts, of which the self-reported Center for Epidemiologic Studies - Depression (CES-D) scale was only used in the French cohorts (Fig. 1). 


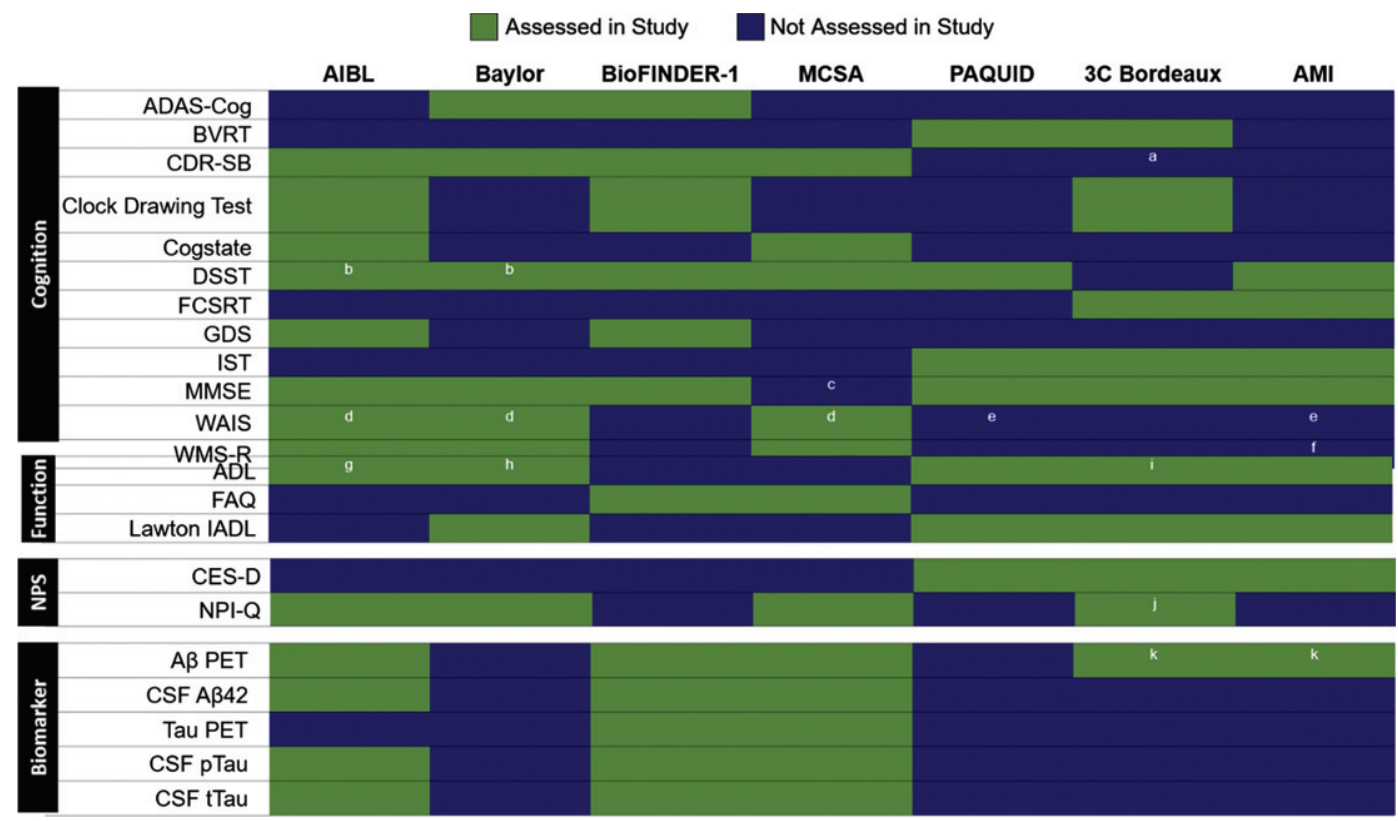

Fig. 1. Assessments conducted in at least two of the CONCORD-AD cohorts. Includes assessments performed in cohort studies in different geographic regions. A $\beta$, amyloid- $\beta$; AD, Alzheimer's disease; ADAS-Cog, Alzheimer's Disease Assessment Scale-Cognitive subscale; ADL, Activities of daily living; AIBL, Australian Imaging, Biomarkers \& Lifestyle Flagship Study of Ageing; AMI, AGRICA-MSA-Institut fédératif de recherche en santé publique/Aging Multidisciplinary Investigation; BioFINDER-1, Biomarkers For Identifying Neurodegenerative Disorders Early and Reliably; BVRT, Benton Visual Retention test; CDR-SB, Clinical Dementia Rating-Sum of Boxes; CES-D, Centre for Epidemiologic Studies Depression; CSF, cerebrospinal fluid; CU, cognitively unimpaired; DSST, Digit Symbol Substitution Test; FAQ, Functional Assessment Questionnaire; FCSRT, Free and Cued Selective Reminding Test; GDS, Geriatric Depression Scale; IADL, Instrumental Activities of Daily Living; IST, Isaacs Set Test; MCI, mild cognitive impairment; MCSA, Mayo Clinic Study of Aging; MINI, Mini-International Neuropsychiatric Interview; MMSE, Mini-Mental State Examination; ND, non-demented; NPI-Q, Neuropsychiatric Inventory Questionnaire; NPS, neuropsychiatric symptoms; PET, positron emission tomography; pTau, phosphorylated tau; tTau, total tau; WAIS-III, Wechsler Adult Intelligence Scale-Third Edition; WAIS-R, Wechsler Adult Intelligence Scale-Revised; WMS-R, Wechsler Memory Scale-Revised; 3C Bordeaux, Three-City Study. ${ }^{\text {a}}$ Used in the COGICARE sub-study of 3C Bordeaux in all participants with dementia; ${ }^{b}$ DSST can be derived from the WAIS-R used in Baylor and from WAIS-III in AIBL; ${ }^{\mathrm{c}}$ MMSE score can be derived from the Short Test of Mental Status used in MCSA; ${ }^{\mathrm{d}}$ WAIS-R in Baylor, WAIS-III in AIBL; ${ }^{\mathrm{e}}$ Wechsler similarities test used; ${ }^{\mathrm{f}}$ Wechsler story memory test; ${ }^{\mathrm{g}} \mathrm{ADL}$ Inventory; ${ }^{\mathrm{h}}$ Lawton and Brody instrumental ADL Scales; ${ }^{\mathrm{i}}$ Katz scale; ${ }^{\mathrm{j}}$ Short form used in the COGICARE sub-study of $3 \mathrm{C}$; ${ }^{\mathrm{k}}$ Amyloid-PET available only on a subsample at the follow-up.

\section{Cognitive impairment across the AD spectrum}

MMSE scores at baseline were similar in CU participants from AIBL, Baylor, and BioFINDER1 cohorts (median range 29-30). Notably, these studies all included participants from memory clinics. Participants in the community-based MCSA, 3C Bordeaux, PAQUID, and AMI (non-demented) cohorts had a wider range of scores (median range 26-28) (Fig. 2A). As expected, in both clinicand community-based cohorts, there was progressive worsening in MMSE scores in the MCI group (median range 25-28) and $\mathrm{AD}$ dementia participants (median range 15-22) (Fig. 2B, C). In the four cohorts that also utilized CDR-SB to monitor disease progression, baseline CDR-SB scores for CU individuals were low, with a median score of 0 for all cohorts except the Baylor study (median 1, Supplementary Figure 1). As with the MMSE, there was progressive worsening in the MCI (median range 0.5-1.5) and $\mathrm{AD}$ dementia groups (median both 6) (Supplementary Figure 1B, 1C).

\section{Functional impairment measures varied across the cohorts}

A variety of scales were used to assess functional impairment in the CONCORD-AD network; therefore, direct score comparisons of functional impairments were not possible in this report. Baseline functional assessments in the COGICARE ancillary study of the $3 \mathrm{C}$ cohort showed that among participants living in the community, those with dementia had higher rates of moderate (4-IADL 


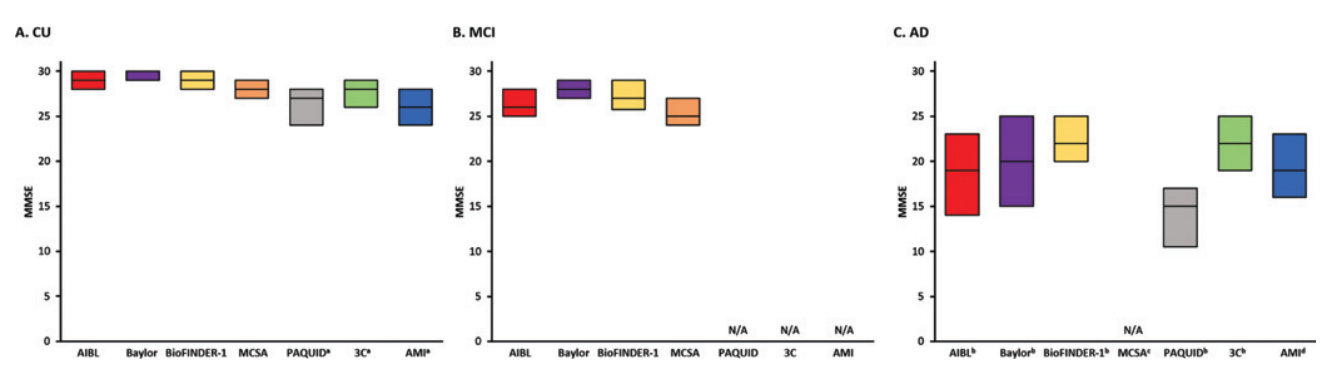

Fig. 2. Comparison of baseline MMSE scores across the cohorts in (A) CU, (B) MCI, and (C) AD participants. Note that for population-based cohorts, $\mathrm{AD}$ at baseline are prevalent cases, and not incident cases or cases recently referred to a memory clinic. AD, Alzheimer's disease; AIBL, Australian Imaging, Biomarkers \& Lifestyle Flagship Study of Ageing; AMI, AGRICA-MSA-Institut fédératif de recherche en santé publique/Aging Multidisciplinary Investigation; Baylor, Alzheimer's Disease and Memory Disorders Center at Baylor College of Medicine; BioFINDER-1, Biomarkers For Identifying Neurodegenerative Disorders Early and Reliably; CU, cognitively unimpaired; MCSA, Mayo Clinic Study of Aging; MMSE, Mini-Mental State Examination; ND, no data; PAQUID, Personnes Agées QUID; 3C Bordeaux, ThreeCity Study. ${ }^{a}$ The PAQUID, 3C Bordeaux and AMI studies scores are presented of non-demented participants; ${ }^{\mathrm{b}}$ The AIBL, Baylor, and BioFINDER-1, data presented is specific to AD dementia (clinically defined AD or biomarker-confirmed AD; BioFINDER-1 includes AD with other pathologies where AD is the dominant etiology); ${ }^{\mathrm{c}} \mathrm{MCSA}$ included dementia of any cause; ${ }^{\mathrm{d}} 3 \mathrm{C}$ Bordeaux, PAQUID, and AMI included $\mathrm{AD}$ or $\mathrm{AD}$ plus another form of dementia (with another type of lesion or atypical clinical presentation).

score $=3 ; 14.4 \%$ ) or severe IADL disability (4IADL score $=4 ; 64.0 \%$ ), compared with $5.2 \%$ and $2.6 \%$, respectively in those with MCI (MCI status retrospectively assigned for this specific analysis). The ADL impairment was associated with increased risk of moderate-to-severe caregiver burden. Functional decline was evaluated in the MCSA (measured with the Functional Activities Questionnaire [FAQ] and the CDR-SB functional domains) and Baylor (IADL and the Lawton and Brody Physical SelfMaintenance Scale [PSMS]) studies. In the MCSA, more pronounced functional limitations and decline correlated with elevated brain amyloid and neurodegeneration $[63,64]$. Interestingly in a temporal assessment of 5-year functional decline rate of individuals with probable $\mathrm{AD}$ from the Baylor study, more recent cohorts (2005-2009) had a lower rate of functional decline in PSMS (but not IADL) than earlier participants (1994-1999 and 2000-2004).

\section{Occurrence of neuropsychiatric symptoms across different stages of $A D$}

Data on NPS collected using the Neuropsychiatric Inventory Questionnaire (NPI-Q) were available from MCSA (in those with positron emission tomography [PET] imaging for current report), COGICARE sub-study of 3C, and Baylor cohorts. Dysphoria/depression, anxiety, apathy/indifference, and irritability/lability were the most common NPS overall (Fig. 3) [65]. Psychotic symptoms such as hallucinations and euphoria/elation were less common overall. The frequency of NPS generally increased with severity of disease (Fig. 3). In the MCSA cohort, NPS were reported at a higher rate in the MCI group than CU individuals for all NPS, except euphoria/elation which had similarly low rates in both groups. Similarly, in the Baylor study in participants who had progressed to dementia, all NPS were more frequent in the moderate $\mathrm{AD}$ dementia group compared with mild $\mathrm{AD}$ dementia.

\section{Amyloid and tau assessments}

The availability of neuroimaging and fluid biomarker data varied substantially across the cohorts (Table 2). The AIBL, BioFINDER-1, and MCSA studies routinely collected longitudinal data on amyloid PET as well as cerebrospinal fluid (CSF) $\mathrm{A} \beta_{42}$, pTau, and tTau in subsets of participants; CSF biomarker data were collected for over $90 \%$ of participants in BioFINDER-1. In contrast, biomarker data were not systematically collected in the Baylor study and French cohorts. Amyloid PET, but no other biomarkers, was assessed in a subset of participants in the 3C Bordeaux (49 non-demented participants, 4 AD participants) and AMI studies (61 non-demented participants) at 14 years and 7 years, respectively. Tau PET was only assessed in the BioFINDER-1 and MCSA cohorts.

\section{CHALLENGES OF CROSS-COHORT STUDIES}

Although established $\mathrm{AD}$ cohorts offer a rich potential for increased understanding of $\mathrm{AD}$ risk 

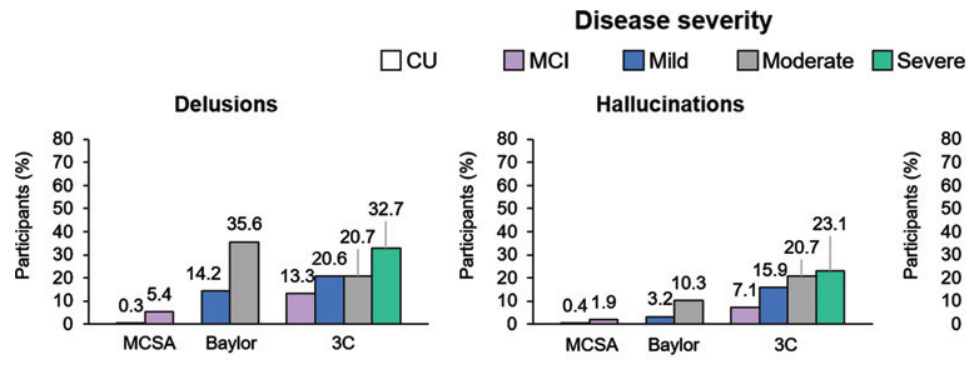

Anxiety

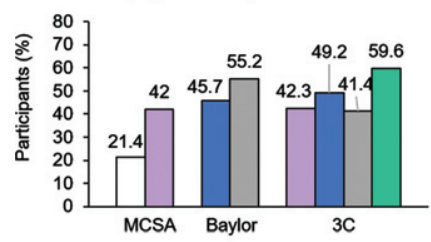

Apathy/indifference

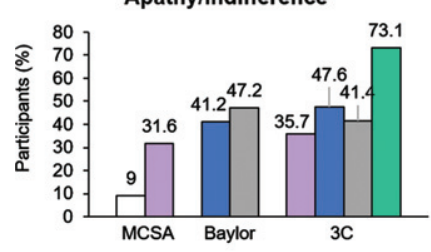

Aberrant motor behavior

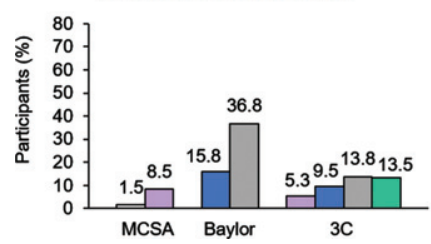

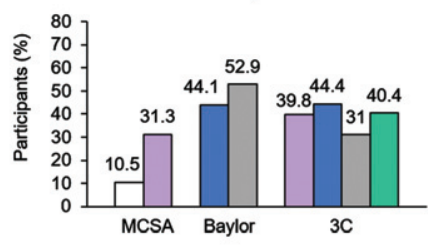

Disinhibition

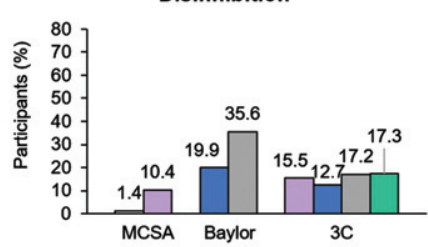

Sleep and night time behaviour change

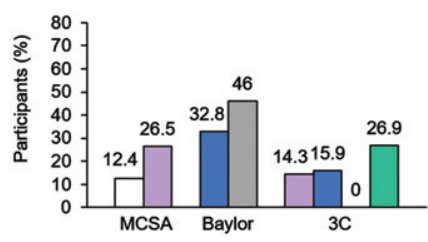

Agitation/aggression

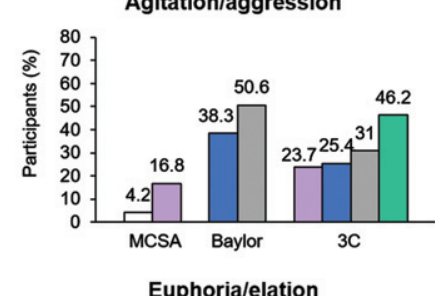

Euphoria/elation

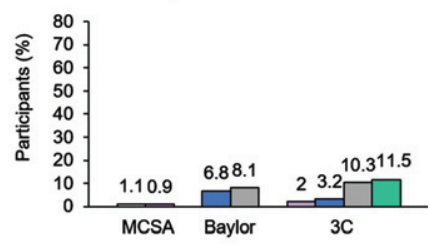

Irritability/lability

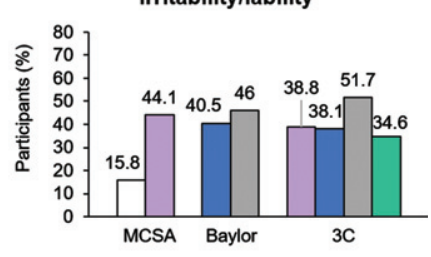

Appetite/eating change

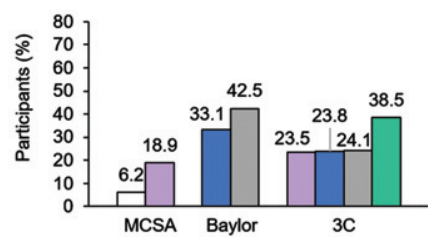

Fig. 3. Frequency of NPS, as assessed by NPI-Q, and displayed by disease stage in the MCSA ${ }^{\mathrm{a}}, 3 \mathrm{C}^{\mathrm{b}}$, and Baylor cohorts ${ }^{\mathrm{c}}$. AD, Alzheimer's Disease; MCSA, Mayo Clinic Study of Aging; Baylor, Alzheimer's Disease and Memory Disorders Center at Baylor College of Medicine; CU, cognitively unimpaired; MCI, mild cognitive impairment; 3C, Three-City Study; NPI-Q, Neuropsychiatric Inventory-Questionnaire;

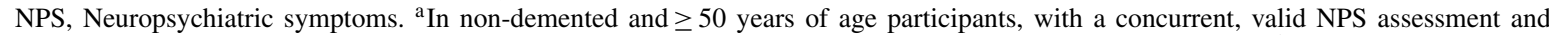
amyloid positron emission tomography (PET) neuroimaging. MCSA data have been reported previously [65]; ${ }^{b}$ Results presented from COGICARE, a sub-study of $3 \mathrm{C} ;{ }^{\mathrm{c}}$ Data were not available from the other cohorts.

factors, clinical heterogeneity, and disease progression, the challenges of cross-cohort studies must be examined.

\section{Establishing cohort studies}

It is important to acknowledge that existing cohorts have not been established according to a uniform set of aims and using the same methods, and that individual cohort studies have unique hurdles to overcome. The design and conduct of cross-cohort studies must be conducted in accordance with regional and national guidelines, which vary not only with geography but also over time. Moreover, as longitudinal studies can be conducted for decades, there will be multiple protocol changes and adjustments needed to align with evolving guidelines. Cohort studies require sufficient infrastructure and funding to conduct testing over long intervals, meaning that expensive biomarker and/or imaging analyses may not be feasible, especially for large or geographically dispersed cohorts, or where biomarker characterization is not the primary purpose of the study. Study design can also be informed by previous studies and the evolving knowledge of $\mathrm{AD}$, then tailored to meet new aims. For example, the Swedish BioFINDER-2 study launched in 2017 was designed to complement the pre-existing BioFINDER-1 study and address emerging issues regarding the role of tau pathology in different dementias and in their preclinical stages 
Table 2

Availability of systematically collected biomarker data at baseline and/or follow-up in CONCORD-AD network cohorts

\begin{tabular}{|c|c|c|c|c|c|c|c|c|c|}
\hline \multirow[t]{2}{*}{ Biomarker } & \multicolumn{3}{|c|}{ AIBL } & \multicolumn{3}{|c|}{ BioFINDER-1 } & \multicolumn{2}{|c|}{$\mathrm{MCSA}^{\mathrm{a}, \mathrm{d}}$} & \multirow[b]{2}{*}{$A D$} \\
\hline & $C U$ & $M C I$ & $A D$ & $C U^{b}$ & $M C I$ & $A D$ & $C U$ & $M C I$ & \\
\hline \multicolumn{10}{|c|}{ Measures of $A \beta, n(\%)$} \\
\hline PET & $145(12)^{\mathrm{c}}$ & $36(12)^{\mathrm{c}}$ & $19(6)^{\mathrm{c}}$ & $272(33)$ & $169(58)$ & N/A & $1,592(39)^{\mathrm{c}}$ & $156(28)^{\mathrm{c}}$ & N/A \\
\hline $\mathrm{CSF} A \beta_{42}$ & $27(2)$ & $33(11)$ & $140(44)$ & $797(96)$ & $288(99)$ & $93(100)$ & $719(18)^{\mathrm{c}}$ & $64(11)$ & N/A \\
\hline \multicolumn{10}{|c|}{ Measures of Tau, $n(\%)$} \\
\hline PET & N/A & N/A & N/A & 52 & 42 & 2 & $579(14)^{\mathrm{c}}$ & $35(6)$ & N/A \\
\hline CSF pTau & $27(2)$ & $33(11)$ & $140(44)$ & $797(96)$ & $288(99)$ & $93(90)$ & $719(18)^{\mathrm{c}}$ & $64(11)$ & N/A \\
\hline CSF tTau & $27(2)$ & $33(11)$ & $140(44)$ & 797 (96) & $288(99)$ & $93(100)$ & $719(18)^{\mathrm{c}}$ & $64(11)$ & N/A \\
\hline
\end{tabular}

A $\beta$, amyloid- $\beta$; AD, Alzheimer's disease; AIBL, Australian Imaging, Biomarkers \& Lifestyle Flagship Study of Ageing; AMI, AGRICAMSA-Institut fédératif de recherche en santé publique/Aging Multidisciplinary Investigation; BioFINDER-1, Biomarkers For Identifying Neurodegenerative Disorders Early and Reliably; CSF, cerebrospinal fluid; CU, cognitively unimpaired; MCI, mild cognitive impairment; MCSA, Mayo Clinic Study of Aging; N/A, not available; ND, non-demented; PET, positron emission tomography; pTau, phosphorylated tau; tTau, total tau; 3C Bordeaux, Three-City Study. ${ }^{a}$ In MCSA, PET and/or CSF biomarkers could be available at baseline and/or follow-up visits and not necessarily at the same study visit, as participants can select if they would like to undergo PET scans and/or lumbar puncture every time they visit the study. Follow-up visits occur every 15 months and neuroimaging studies are offered every 30 months or sooner if

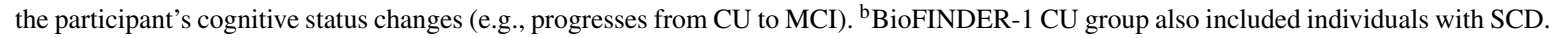
${ }^{\mathrm{c}}$ Longitudinal data available. ${ }^{\mathrm{d}} \mathrm{MCSA}$ did not actively follow-up participants diagnosed with dementia at study baseline.

[66]. While BioFINDER-2 was not included in the current CONCORD-AD Network, potential future collaborations with this and other recently established longitudinal studies, could increase the breadth and depth of data in the future.

\section{Heterogeneous study designs}

The CONCORD-AD collaboration model involves the sharing of independently conducted analyses to address key questions about disease progression, and patient-related outcomes in diverse patient populations, including both population- and communitybased cohorts. This model facilitates evaluation of the impact of population and disease heterogeneity (e.g., geographic, educational, sociological, and cultural variations, study inclusion/exclusion criteria) on critical scientific questions. The included studies had a variety of aims, affecting study design and choice of assessments. This heterogeneity of assessments, while expected, limited the direct cross-comparison of cohorts and capacity for integration of patient-level data.

\section{Diagnostic challenges}

Dementia diagnosis methodologies and thresholds for impairment also differed between studies and, notably, have evolved and improved since the start of some of the older studies such as PAQUID, which was established more than 10 years before some of the other cohorts included. Participants with dementia may now be diagnosed at earlier and milder stages compared with 30 years ago $[67,68]$.

The guidelines for diagnosis of MCI have also evolved over time and definitions differ between cohorts. In the CONCORD-AD network, prospective MCI groups were not assessed in the three French cohort studies, and either the Winblad [69] or Petersen criteria $[70,71]$ were used to define MCI in the remaining four cohorts. Although a potentially attractive idea, retrospective definition of an MCI group for cross-cohort comparison is problematic due to incomplete neuropsychological assessments, fluctuating cognition at visits, or missing information on comorbidities that may impact cognition. Diagnosing, and subsequently monitoring, MCI in a population-based study may be complex, particularly if the affected person does not report a cognitive complaint [72]. This may be compounded by social and cultural differences around what is felt to be "normal" for age, and perceived functional impairments associated with mild memory decline that may limit the reliability of caregivers to confirm problematic cognitive decline.

\section{Challenges associated with early detection in Alzheimer's disease and dementia}

International collaborations have the potential to leverage diverse clinical data in a variety of patient populations which ultimately could inform healthservice planning for optimal early detection of cognitive decline. However, there are several challenges associated with early detection. Currently, in 
practice, $\mathrm{AD}$ is diagnosed with a variety of questionnaires that aim to measure memory function and neuroimaging tools, among other assessments [73]. The assessment of physical function is not routinely performed in practice, and thus an early-to-handle objective physical function test such as the Short Physical Performance Battery (SPPB) may provide useful prognostic information in the elderly population [74]. Additionally, differentiating between the normal course of aging versus the disease pathway seen in $\mathrm{AD}$ and dementia in the general population is an additional challenge for practitioners. Data suggest that screening for $\mathrm{AD}$ and related dementias in primary care to identify signs of early disease onset could allow for more timely intervention [75]. The CONCORD-AD network highlights the need for longitudinal tracking of at-risk individuals in order to provide early preventive interventions. Suitable, short cognitive screening tools for people thought to have MCI are lacking, e.g., the RAPCOG program aims to develop and validate screening tools for use in both MCI and dementia populations [76]. Digital assessments such as the Cogstate Brief Battery may be harnessed to develop registries of individuals at risk for $\mathrm{AD}$ and may inform use in the primary care setting [77].

\section{Comparing clinic- and community-based cohorts}

Populations derived from specialist memory clinics differ from community cohorts as a result of differences in the demographics of individual participants, self-referral and healthcare professional-referral patterns, and differential access to healthcare services [78]. For example, more pronounced variations in MMSE were observed in CU participants in the population-based cohorts of MCSA, PAQUID, and 3C Bordeaux; notably, this variation was no longer observed in those with $\mathrm{AD}$ dementia. As for other forms of assessment, there is an inevitable disparity between cohorts due to inherent differences in study aims and designs.

The variability observed among cohorts highlights the impact of differing recruitment procedures and inclusion criteria. In clinical trials, with even more tailored inclusion and exclusion criteria, the trial population can greatly diverge from the original source population. By necessity, clinical trials often exclude those with comorbidities. This results in the recruitment of participants that may be healthier than the typical aging population, which could impact disease progression as captured by measures of cognitive and functional decline. Variations identified during crosscohort comparisons could help further inform clinical trial design and recruitment in global clinical trials in order to include appropriate participants. These variations can also be mined for hypotheses related to the quantitative impact of methodologic or demographic difference on biomarkers or outcome measures.

\section{Data analysis}

Cross-cohort comparisons also face challenges relating to the practical logistics of data sharing and data governance. While we can be mindful of differences in the study populations and timelines when looking at cross-cohort comparisons, it is not always easy or straightforward to combine data from different sources. The methodological challenges of analyzing and interpreting combined datasets can be lessened by describing the data for each cohort in detail, including the sources of the data, taking into account any specific underlying reasons for differences among cohorts, and clear communication from cohort investigators on potential caveats or limitations in the analysis and therefore subsequent interpretation of findings. The CONCORD-AD collaborative network eased difficulties in logistics surrounding data protection by sharing data summaries compiling population-level data for analysis rather than patient-level data, as shared in the GAAIN network.

\section{OPPORTUNITIES FOR CROSS-COHORT STUDIES}

The primary advantage of the CONCORD-AD network is that it is a resource with a sufficiently large sample size to confirm or replicate findings of other studies and explore potential causes of heterogeneity in measures of interest, such as cognitive outcomes or rate of disease progression. Such a large cohort that includes patients across the wide spectrum of the AD disease course lends itself to be used for verification and replication of findings seen in smaller clinical trials. While data combined across the cohorts is not currently available, a potential future application of the CONCORD-AD network is harmonization of data to transparently integrate multiple pseudonymized data sources into a single federated database for use by researchers both within and outside the network. This could allow users to remotely access geographically dispersed data while ensuring data security and privacy. 
Secondly, there are also research applications that could be addressed within collaboration projects in the future. This could include data collaboration comparing the CONCORD-AD network with the natural history of $\mathrm{AD}$, from preclinical through clinical stages of disease. This continues to be a major research area of interest with key goals to increase understanding of: 1) cognitive and functional decline in slower and faster progressors along the AD continuum in globally representative cohorts; 2) the natural history of biomarker levels within the disease continuum; and 3) cognitive decline in the presence/absence of key biomarkers, vascular lesions, and comorbidities, and how these relate to major events within the AD continuum (e.g., dependency, institutionalization, death). All of these would improve our understanding of the multiple pathological processes leading to cognitive decline in $\mathrm{AD}$ and other non-AD-related dementias and processes underlying resilience to age-related disease processes $[79,80]$. Thirdly, networks of cohort studies could also enable larger-scale characterization of a population of individuals at high risk for developing $\mathrm{MCI}$ and $\mathrm{AD}$ early in their disease course through the collection of longitudinal data in both cognitive and functional trajectories across disease stages. At present, there is varied consensus on the characterization of various $\mathrm{AD}$ subcategories, resulting in discrepancies in disease classification (i.e., MCI, prodromal AD) across clinical trials and in practice [81]. Comparing large-scale datasets across networks can improve our understanding of the core factors driving conversion from $\mathrm{CU}$ to $\mathrm{MCI}$ to $\mathrm{AD}$ and allow for improved disease classification with the aim of diagnosing patients earlier. Furthermore, data from highly harmonized cohorts could also provide an opportunity to quantify variance around a particular measure, such as annualized change in an assessment score, and to generate hypotheses regarding relative contributions of specific methodological differences to these variances.

This report raises awareness of the need to align cohort study designs in order to facilitate cross-cohort comparison, but further advances can also be made in analysis and interpretation of current data. Current biomarker data can be applied to analyses of core AD biomarkers, such as phosphorylated tau, to monitor disease progression [82]. Additionally, there are encouraging developments into a variety of other biomarkers that require validation [82]. Exploring existing biomarker data with different analytic techniques, such as using centiloid-based analyses to look at the degree of amyloid-positivity rather than binary amyloid-positive or -negative status, can enrich the information yielded by the cohorts. Additionally, investigating the potential utility of composite cognitive and functional endpoints in the CONCORD-AD network [16] and further subdivision of cognitive and functional measures may improve tracking of disease progression. By further exploring the changes in existing and novel biomarkers or clinical endpoints in large, collaborative studies, the data generated may improve our understanding of the clinical course of disease, to ultimately improve timely detection of $\mathrm{AD}$ and to better assess the effectiveness of interventions in $\mathrm{AD}$.

\section{CONCLUSION}

CONCORD-AD was created as an approach to mitigate the impact of $\mathrm{AD}$ on society, by bringing together global resources and expertise with the purpose of generating insights that can improve understanding of the natural history of the disease, inform design of clinical trials at all stages of the disease, and inform health-service planning for optimal patient access to new disease-modifying therapies once they become available. Expansion of these types of networks could be done to include other well-characterized and diverse cohorts representing a wide range of socioeconomic, ethnic, and geographic groups across the $\mathrm{AD}$ continuum, as well as closer alignment in data collection in future studies. This would further strengthen the research community's potential to better understand, and eventually conquer, $\mathrm{AD}$.

\section{ACKNOWLEDGMENTS}

The CONCORD-AD collaboration network is funded by F. Hoffmann-La Roche Ltd., Basel, Switzerland.

Core funding for the AIBL study was provided by the CSIRO Flagship Collaboration Fund and the Science and Industry Endowment Fund (SIEF) in partnership with the CRC for Mental Health, Edith Cowan University, Mental Health Research institute, Dementia Australia, National Ageing Research Institute, Austin Health, Macquarie University, CogState Ltd, Hollywood Private Hospital, and Sir Charles Gairdner Hospital. The study also received funding from the National Health and Medical Research Council (NHMRC), Dementia Collaborative Research Centres program, and 
McCusker Alzheimer's Research Foundation, and operational infrastructure support from the Government of Victoria.

The Baylor cohort has been supported by NIH P50 AG08664, the Texas Alzheimer's Research and Care Consortium, and the Effie Marie Cain endowment.

BioFINDER-1: Work at the authors' research center was supported by the Swedish Research Council, the Knut and Alice Wallenberg foundation, the Marianne and Marcus Wallenberg foundation, the Strategic Research Area MultiPark (Multidisciplinary Research in Parkinson's disease) at Lund University, the Swedish Alzheimer Foundation, and the Swedish Brain Foundation.

MCSA was supported by the NIH (U01 AG006786, P50 AG016574, P30 AG062677, R37 AG011378, R01 AG041851, R01 NS097495), the Alexander Family Alzheimer's Disease Research Professorship of the Mayo Clinic, the Liston Award, the Schuler Foundation, the GHR Foundation, and the Mayo Foundation for Medical Education and Research; and was made possible by the Rochester Epidemiology Project (R01 AG034676).

PAQUID was supported by AGRICA, ARMA (Bordeaux); Caisse Nationale d'Assurance Maladie des Travailleurs Salariés (CNAMTS); Caisse Nationale de Solidarité pour l'Autonomie (CNSA); Conseil Général de la Dordogne; Conseil Général de la Gironde; Conseil Régional d' Aquitaine; Fondation de France; France Alzheimer (Paris); GIS Longévité; Institut National de la Santé et de la Recherche Médicale (INSERM); IPSEN France; Mutuelle Générale de l'Éducation Nationale (MGEN); Mutualité Sociale Agricole (MSA); Novartis Pharma (France); and SCOR Insurance (France). Institut de recherche en santé publique (IReSP), Association France Alzheimer.

The Three-City study is conducted under a partnership agreement between the Institut National de la Santé et de la Recherche Médicale (INSERM), the University Bordeaux 2 Victor Segalen and SanofiAventis. The Fondation pour la Recherche Médicale funded the preparation and initiation of the study. The Three-City study is also supported by the Caisse Nationale Maladie des Travailleurs Salariés, Direction Générale de la Santé, MGEN, Institut de la Longévité, Conseils Régionaux d'Aquitaine et Bourgogne, Fondation de France, Ministry of Research-INSERM Programme "Cohortes et collections de données biologiques", Agence Nationale de la Recherche ANR PNRA 2006 and LongVie 2007, the "Fondation Plan Alzheimer" (FCS 2009-2012), the Caisse Nationale de Solidarité pour l'Autonomie (CNSA) and Roche.

AMI was funded by AGRICA (CAMARCA, CRCCA, CCPMA PREVOYANCE, CPCEA, AGRI PREVOYANCE), la Mutualité Sociale Agricole (MSA) de Gironde, la Caisse Centrale de la Mutualité Sociale Agricole (CCMSA), Caisse Nationale de Solidarité pour l'Autonomie (CNSA) and SCOR Insurance (France). The neur-imaging AMImage1 and AMImage 2 projects were funded by the Programme Hospitalier de Recherche Clinique - PHRC 2008 (Sponsor's code CHUBX 2008/13) and PHRC 2011 (Sponsor's code CHUBX 2011/15).

Medical writing support for the development of this publication was provided by Sarah Engelberth, PhD, and Rachel Johnson, PhD, funded by F. Hoffmann-La Roche Ltd.

Authors' disclosures available online (https:// www.j-alz.com/manuscript-disclosures/21-0525r1).

\section{SUPPLEMENTARY MATERIAL}

The supplementary material is available in the electronic version of this article: https://dx.doi.org/ 10.3233/JAD-210525.

\section{REFERENCES}

[1] Mayeux R, Stern Y (2012) Epidemiology of Alzheimer disease. Cold Spring Harb Perspect Med 2, a006239.

[2] Patterson C (2018) World Alzheimer Report 2018. The state of the art of dementia research: New frontiers. Alzheimer's Disease International, London.

[3] GBD 2015 Neurological Disorders Collaborator Group (2017) Global, regional, and national burden of neurological disorders during 1990-2015: A systematic analysis for the Global Burden of Disease Study 2015. Lancet Neurol 16, 877-897.

[4] Barnes DE, Yaffe K (2011) The projected effect of risk factor reduction on Alzheimer's disease prevalence. Lancet Neurol 10, 819-828.

[5] Aisen P, Touchon J, Andrieu S, Boada M, Doody R, Nosheny RL, Langbaum JB, Schneider L, Hendrix S, Wilcock G, Molinuevo JL, Ritchie C, Ousset PJ, Cummings J, Sperling R, DeKosky ST, Lovestone S, Hampel H, Petersen R, Legrand V, Egan M, Randolph C, Salloway S, Weiner M, Vellas B (2016) Registries and cohorts to accelerate early phase Alzheimer's trials. A report from the E.U./U.S. Clinical Trials in Alzheimer's Disease Task Force. J Prev Alzheimers Dis 3, 68-74.

[6] Chibnik LB, Wolters FJ, Bäckman K, Beiser A, Berr C, Bis JC, Boerwinkle E, Bos D, Brayne C, Dartigues JF, Darweesh SKL, Debette S, Davis-Plourde KL, Dufouil C, Fornage M, Grasset L, Gudnason V, Hadjichrysanthou C, Helmer C, Ikram MA, Ikram MK, Kern S, Kuller LH, Launer L, Lopez OL, Matthews F, Meirelles O, Mosley T, Ower A, Psaty BM, Satizabal CL, Seshadri S, Skoog I, Stephan BCM, Tzourio C, Waziry R, Wong MM, Zettergren A, Hofman A (2017) 
Trends in the incidence of dementia: Design and methods in the Alzheimer Cohorts Consortium. Eur J Epidemiol 32, 931-938.

[7] Wolters FJ, Chibnik LB, Waziry R, Anderson R, Berr C, Beiser A, Bis JC, Blacker D, Bos D, Brayne C (2020) Twenty-seven-year time trends in dementia incidence in Europe and the United States: The Alzheimer Cohorts Consortium. Neurology 95, e519-e531.

[8] Samieri C, Morris M-C, Bennett DA, Berr C, Amouyel P, Dartigues J-F, Tzourio C, Chasman DI, Grodstein F (2018) Fish intake, genetic predisposition to Alzheimer disease, and decline in global cognition and memory in 5 cohorts of older persons. Am J Epidemiol 187, 933-940.

[9] Lim ASP, Gaiteri C, Yu L, Sohail S, Swardfager W, Tasaki S, Schneider JA, Paquet C, Stuss DT, Masellis M, Black SE, Hugon J, Buchman AS, Barnes LL, Bennett DA, De Jager PL (2018) Seasonal plasticity of cognition and related biological measures in adults with and without Alzheimer disease: Analysis of multiple cohorts. PLoS Med 15, e1002647.

[10] Buckley RF, Sikkes S, Villemagne VL, Mormino EC, Rabin JS, Burnham S, Papp KV, Doré V, Masters CL, Properzi MJ, Schultz AP, Johnson KA, Rentz DM, Sperling RA, Amariglio RE (2019) Using subjective cognitive decline to identify high global amyloid in community-based samples: A cross-cohort study. Alzheimers Dement (Amst) 11, 670-678.

[11] Global Alzheimer's Association Interactive Network (GAAIN), Alzheimer's Association, Laboratory of Neuro Imaging (LONI), University of Southern California (USC), Global Alzheimer's Association Interactive Network (GAAIN) Platform, http://www.gaain.org/about.

[12] Ellis KA, Bush AI, Darby D, De Fazio D, Foster J, Hudson P, Lautenschlager NT, Lenzo N, Martins RN, Maruff P, Masters C, Milner A, Pike K, Rowe C, Savage G, Szoeke C, Taddei K, Villemagne V, Woodward M, Ames D, AIBL Research Group (2009) The Australian Imaging, Biomarkers and Lifestyle (AIBL) study of aging: Methodology and baseline characteristics of 1112 individuals recruited for a longitudinal study of Alzheimer's disease. Int Psychogeriatr 21, 672-687.

[13] Chételat G, Villemagne VL, Bourgeat P, Pike KE, Jones G, Ames D, Ellis KA, Szoeke C, Martins RN, O'Keefe GJ, Salvado O, Masters CL, Rowe CC, Australian Imaging Biomarkers and Lifestyle Research Group (2010) Relationship between atrophy and beta-amyloid deposition in Alzheimer disease. Ann Neurol 67, 317-324.

[14] Bourgeat P, Doré V, Fripp J, Ames D, Masters CL, Salvado O, Villemagne VL, Rowe CC, AIBL research group (2018) Implementing the centiloid transformation for $11 \mathrm{C}-\mathrm{PiB}$ and $\beta$-amyloid 18F-PET tracers using CapAIBL. Neuroimage 183, 387-393.

[15] Burnham SC, Coloma P, Li Q-X, Collins S, Savage G, Laws S, Doecke J, Maruff P, Martins R, Ames D, Masters C, Villemagne V (2019) Application of the NIA-AA research framework: Towards a biological definition of Alzheimer's disease using cerebrospinal fluid biomarkers in the AIBL study. J Prev Alzheimers Dis 6, 248-255.

[16] Burnham SC, Raghavan N, Wilson W, Baker D, Ropacki MT, Novak G, Ames D, Ellis K, Martins RN, Maruff P, Masters CL, Romano G, Rowe CC, Savage G, Macaulay SL, Narayan VA, Alzheimer's Disease Neuroimaging Initiative, AIBL Research Group (2015) Novel statisticallyderived composite measures for assessing the efficacy of disease-modifying therapies in prodromal Alzheimer's disease trials: An AIBL study. J Alzheimers Dis 46, 10791089.

[17] Baker JE, Pietrzak RH, Laws SM, Ames D, Villemagne VL, Rowe CC, Masters CL, Maruff P, Lim YY (2019) Visual paired associate learning deficits associated with elevated beta-amyloid in cognitively normal older adults. Neuropsychology 33, 964-974.

[18] Venkatraman VK, Sanderson A, Cox KL, Ellis KA, Steward C, Phal PM, Gorelik A, Sharman MJ, Villemagne VL, Lai M, Cyarto EV, Merkel B, Ames D, Szoeke C, Rowe CC, Masters CL, Lautenschlager NT, Desmond PM (2020) Effect of a 24-month physical activity program on brain changes in older adults at risk of Alzheimer's disease: The AIBL active trial. Neurobiol Aging 89, 132-141.

[19] Doody R, Pavlik V, Massman P, Kenan M, Yeh S, Powell S, Cooke N, Dyer C, Demirovic J, Waring S, Chan W (2005) Changing patient characteristics and survival experience in an Alzheimer's center patient cohort. Dement Geriatr Cogn Disord 20, 198-208.

[20] Doody RS, Pavlik V, Massman P, Rountree S, Darby E, Chan W (2010) Predicting progression of Alzheimer's disease. Alzheimers Res Ther 2, 14.

[21] Strite D, Massman PJ, Cooke N, Doody RS (1997) Neuropsychological asymmetry in Alzheimer's disease: Verbal versus visuoconstructional deficits across stages of dementia. J Int Neuropsychol Soc 3, 420-427.

[22] Alverson WA, Massman PJ, Doody RS (2016) Prevalence and correlates of cognitive asymmetry in a large sample of Alzheimer's disease patients. J Clin Exp Neuropsychol 38, 516-526.

[23] Sood A, Pavlik V, Darby E, Chan W, Doody R (2021) Different cognitive profiles are associated with progression rate and age at death in probable Alzheimer's disease. $J$ Alzheimers Dis 80, 735-747.

[24] Massman PJ, Doody RS (1996) Hemispheric asymmetry in Alzheimer's disease is apparent in motor functioning. J Clin Exp Neuropsychol 18, 110-121.

[25] Doody RS, Vacca JL, Massman PJ, Liao T-y (1999) The influence of handedness on the clinical presentation and neuropsychology of Alzheimer disease. Arch Neurol 56, 1133-1137.

[26] Rountree SD, Chan W, Pavlik VN, Darby EJ, Doody RS (2012) Factors that influence survival in a probable Alzheimer disease cohort. Alzheimers Res Ther 4, 16.

[27] The Swedish BioFinder study, Background and aims, http://biofinder.se/background_and_aims/.

[28] Borland E, Nägga K, Nilsson PM, Minthon L, Nilsson ED, Palmqvist S (2017) The Montreal Cognitive Assessment: Normative data from a large Swedish population-based cohort. J Alzheimers Dis 59, 893-901.

[29] Palmqvist S, Zetterberg H, Blennow K, Vestberg S, Andreasson U, Brooks DJ, Owenius R, Hägerström D, Wollmer P, Minthon L, Hansson O (2014) Accuracy of brain amyloid detection in clinical practice using cerebrospinal fluid $\beta$-amyloid 42: A cross-validation study against amyloid positron emission tomography. JAMA Neurol 71, 1282-1289.

[30] Palmqvist S, Zetterberg H, Mattsson N, Johansson P, Alzheimer's Disease Neuroimaging Initiative, Minthon L, Blennow K, Olsson M, Hansson O, Swedish BioFINDER Study Group (2015) Detailed comparison of amyloid PET and CSF biomarkers for identifying early Alzheimer disease. Neurology 85, 1240-1249.

[31] Hansson O, Seibyl J, Stomrud E, Zetterberg H, Trojanowski JQ, Bittner T, Lifke V, Corradini V, Eichenlaub U, Batrla R, 
Buck K, Zink K, Rabe C, Blennow K, Shaw LM, Swedish BioFINDER study group, Alzheimer's Disease Neuroimaging Initiative (2018) CSF biomarkers of Alzheimer's disease concord with amyloid- $\beta$ PET and predict clinical progression: A study of fully automated immunoassays in BioFINDER and ADNI cohorts. Alzheimers Dement 14, 1470-1481.

[32] Palmqvist S, Janelidze S, Stomrud E, Zetterberg H, Karl J, Zink K, Bittner T, Mattsson N, Eichenlaub U, Blennow K, Hansson O (2019) Performance of fully automated plasma assays as screening tests for Alzheimer disease-related $\beta$ amyloid status. JAMA Neurol 76, 1060-1069.

[33] Janelidze S, Pannee J, Mikulskis A, Chiao P, Zetterberg H, Blennow K, Hansson O (2017) Concordance between different amyloid immunoassays and visual amyloid positron emission tomographic assessment. JAMA Neurol 74, 14921501.

[34] Palmqvist S, Schöll M, Strandberg O, Mattsson N, Stomrud E, Zetterberg H, Blennow K, Landau S, Jagust W, Hansson $O$ (2017) Earliest accumulation of $\beta$-amyloid occurs within the default-mode network and concurrently affects brain connectivity. Nat Commun 8, 1214.

[35] Janelidze S, Mattsson N, Stomrud E, Lindberg O, Palmqvist S, Zetterberg H, Blennow K, Hansson O (2018) CSF biomarkers of neuroinflammation and cerebrovascular dysfunction in early Alzheimer disease. Neurology 91, e867-e877.

[36] Jack CR, Jr., Knopman DS, Weigand SD, Wiste HJ, Vemuri P, Lowe V, Kantarci K, Gunter JL, Senjem ML, Ivnik RJ, Roberts RO, Rocca WA, Boeve BF, Petersen RC (2012) An operational approach to National Institute on AgingAlzheimer's Association criteria for preclinical Alzheimer disease. Ann Neurol 71, 765-775.

[37] Knopman DS, Jack CR, Jr., Wiste HJ, Weigand SD, Vemuri P, Lowe V, Kantarci K, Gunter JL, Senjem ML, Ivnik RJ, Roberts RO, Boeve BF, Petersen RC (2012) Short-term clinical outcomes for stages of NIA-AA preclinical Alzheimer disease. Neurology 78, 1576-1582.

[38] Jack CR, Jr., Wiste HJ, Vemuri P, Weigand SD, Senjem ML, Zeng G, Bernstein MA, Gunter JL, Pankratz VS, Aisen PS, Weiner MW, Petersen RC, Shaw LM, Trojanowski JQ, Knopman DS (2010) Brain beta-amyloid measures and magnetic resonance imaging atrophy both predict time-toprogression from mild cognitive impairment to Alzheimer's disease. Brain 133, 3336-3348.

[39] Petersen RC, Lundt ES, Therneau TM, Weigand SD, Knopman DS, Mielke MM, Roberts RO, Lowe VJ, Machulda MM, Kremers WK, Geda YE, Jack CR, Jr. (2019) Predicting progression to mild cognitive impairment. Ann Neurol 85, 155-160.

[40] Kern S, Syrjanen JA, Blennow K, Zetterberg H, Skoog I, Waern M, Hagen CE, van Harten AC, Knopman DS, Jack CR, Jr., Petersen RC, Mielke MM (2019) Association of cerebrospinal fluid neurofilament light protein with risk of mild cognitive impairment among individuals without cognitive impairment. JAMA Neurol 76, 187-193.

[41] Vemuri P, Lesnick TG, Knopman DS, Przybelski SA, Reid RI, Mielke MM, Graff-Radford J, Lowe VJ, Machulda MM, Petersen RC, Jack Cr Jr MD (2019) Amyloid, vascular, and resilience pathways associated with cognitive aging. Ann Neurol 86, 866-877.

[42] Pankratz VS, Roberts RO, Mielke MM, Knopman DS, Jack CR, Jr., Geda YE, Rocca WA, Petersen RC (2015) Predicting the risk of mild cognitive impairment in the Mayo Clinic Study of Aging. Neurology 84, 1433-1442.
[43] Dartigues J-F, Gagnon M, Barberger-Gateau P, Letenneur L, Commenges D, Sauvel C, Michel P, Salamon R (1992) The Paquid epidemiological program on brain ageing. $\mathrm{Neu}$ roepidemiology $\mathbf{1 1}, 14-18$.

[44] Pérès K, Brayne C, Matharan F, Grasset L, Helmer C, Letenneur L, Foubert-Samier A, Baldi I, Tison F, Amieva H, Dartigues J-F (2017) Trends in prevalence of dementia in French farmers from two epidemiological cohorts. $J \mathrm{Am}$ Geriatr Soc 65, 415-420.

[45] Grasset L, Brayne C, Joly P, Jacqmin-Gadda H, Peres K, Foubert-Samier A, Dartigues JF, Helmer C (2016) Trends in dementia incidence: Evolution over a 10 -year period in France. Alzheimers Dement 12, 272-280.

[46] Marioni RE, Proust-Lima C, Amieva H, Brayne C, Matthews FE, Dartigues J-F, Jacqmin-Gadda H (2015) Social activity, cognitive decline and dementia risk: A 20year prospective cohort study. BMC Public Health 15, 1089.

[47] Rullier L, Meillon C, Bergua V, Pimouguet C, Harmand MG-C, Helmer C, Pérès K, Dartigues J-F, Amieva H (2018) A comprehensive approach of the determinants of use of care in dementia: The Recaredem (recourse to care in dementia) cross-sectional study. Int Psychogeriatr 31, 10271037.

[48] Pérès K, Helmer C, Amieva H, Matharan F, Carcaillon L, Jacqmin-Gadda H, Auriacombe S, Orgogozo J-M, Barberger-Gateau P, Dartigues J-F (2011) Gender differences in the prodromal signs of dementia: Memory complaint and IADL-restriction. A prospective populationbased cohort. J Alzheimers Dis 27, 39-47.

[49] Amieva H, Mokri H, Le Goff M, Meillon C, Jacqmin-Gadda H, Foubert-Samier A, Orgogozo J-M, Stern Y, Dartigues J-F (2014) Compensatory mechanisms in higher-educated subjects with Alzheimer's disease: A study of 20 years of cognitive decline. Brain 137, 1167-1175.

[50] Amieva H, Meillon C, Proust-Lima C, Dartigues JF (2019) Is low psychomotor speed a marker of brain vulnerability in late life? Digit Symbol Substitution Test in the prediction of Alzheimer, Parkinson, stroke, disability, and depression. Dement Geriatr Cogn Disord 47, 297-305.

[51] 3C Study Group (2003) Vascular factors and risk of dementia: Design of the Three-City Study and baseline characteristics of the study population. Neuroepidemiology 22, 316-325.

[52] Norton J, Carrière I, Pérès K, Gabelle A, Berr C, Ritchie K, Ancelin M-L (2019) Sex-specific depressive symptoms as markers of pre-Alzheimer dementia: Findings from the Three-City cohort study. Transl Psychiatry 9, 291.

[53] Frison E, Dufouil C, Helmer C, Berr C, Auriacombe S, Chêne G (2019) Diabetes-associated dementia risk and competing risk of death in the three-city study. J Alzheimers Dis 71, 1339-1350.

[54] Ngabirano L, Samieri C, Feart C, Gabelle A, Artero S, Duflos C, Berr C, Mura T (2019) Intake of meat, fish, fruits, and vegetables and long-term risk of dementia and Alzheimer's disease. J Alzheimers Dis 68, 711-722.

[55] Feart C, Helmer C, Merle B, Herrmann FR, Annweiler C, Dartigues J-F, Delcourt C, Samieri C (2017) Associations of lower vitamin $\mathrm{D}$ concentrations with cognitive decline and long-term risk of dementia and Alzheimer's disease in older adults. Alzheimers Dement 13, 1207-1216.

[56] Samieri C, Perier M-C, Gaye B, Proust-Lima C, Helmer C, Dartigues J-F, Berr C, Tzourio C, Empana J-P (2018) Association of cardiovascular health level in older age with cognitive decline and incident dementia. JAMA 320, 657-664. 
[57] Wagner M, Helmer C, Tzourio C, Berr C, Proust-Lima C, Samieri C (2018) Evaluation of the concurrent trajectories of cardiometabolic risk factors in the 14 years before dementia. JAMA Psychiatry 75, 1033-1042.

[58] Pérès K, Matharan F, Allard M, Amieva H, Baldi I, Barberger-Gateau P, Bergua V, Bourdel-Marchasson I, Delcourt C, Foubert-Samier A, Fourrier-Réglat A, Gaimard M, Laberon S, Maubaret C, Postal V, Chantal C, Rainfray M, Rascle N, Dartigues JF (2012) Health and aging in elderly farmers: The AMI cohort. BMC Public Health 12, 558 .

[59] Mokri H, Matharan F, Pérès K, Bouisson J, Dartigues J, Amieva H, Dubois B (2013) The Goblets test: Norms in the elderly population and properties in the detection of cognitive impairment in elderly individuals selected from the general population. Rev Neurol (Paris) 169, 871-878.

[60] Butcher L, Pérès K, André P, Morris RH, Walter S, Dartigues J-F, Rodriguez-Mañas L, Feart C, Erusalimsky JD, FRAILOMIC consortium (2018) Association between plasma CCL11 (eotaxin-1) and cognitive status in older adults: Differences between rural and urban dwellers. Exp Gerontol 113, 173-179.

[61] Kokmen E, Smith GE, Petersen RC, Tangalos E, Ivnik RC (1991) The short test of mental status: Correlations with standardized psychometric testing. Arch Neurol 48, 725-728.

[62] Tang-Wai DF, Knopman DS, Geda YE, Edland SD, Smith GE, Ivnik RJ, Tangalos EG, Boeve BF, Petersen RC (2003) Comparison of the short test of mental status and the minimental state examination in mild cognitive impairment. Arch Neurol 60, 1777-1781.

[63] Vassilaki M, Aakre JA, Kremers WK, Mielke MM, Geda YE, Machulda MM, Knopman DS, Coloma PM, Schauble B, Vemuri P, Lowe VJ, Jack CR, Jr., Petersen RC, Roberts RO (2018) Association between functional performance and Alzheimer's disease biomarkers in individuals without dementia. J Am Geriatr Soc 66, 2274-2281.

[64] Vassilaki M, Aakre JA, Kremers WK, Lesnick TG, Mielke MM, Geda YE, Machulda MM, Knopman DS, Butler L, Traber M (2020) Brain amyloid, cortical thickness, and changes in activities of daily living. Ann Clin Transl Neurol 7, 474-485.

[65] Krell-Roesch J, Vassilaki M, Mielke MM, Kremers WK, Lowe VJ, Vemuri P, Machulda MM, Christianson TJ, Syrjanen JA, Stokin GB, Butler LM, Traber M, Jack CR Jr, Knopman DS, Roberts RO, Petersen RC, Geda YE (2019) Cortical $\beta$-amyloid burden, neuropsychiatric symptoms, and cognitive status: The Mayo Clinic Study of Aging. Transl Psychiatry $\mathbf{9}, 123$.

[66] ClinicalTrials.gov, The Swedish BioFINDER 2 Study (BioFINDER2). ClinicalTrials.gov Identifier: NCT0317 4938, https://clinicaltrials.gov/ct2/show/NCT03174938.

[67] Pérès K, Brayne C, Matharan F, Grasset L, Helmer C, Letenneur L, Foubert-Samier A, Baldi I, Tison F, Amieva H (2017) Trends in prevalence of dementia in French farmers from two epidemiological cohorts. J Am Geriatr Soc 65, 415-420.

[68] Grasset L, Brayne C, Joly P, Jacqmin-Gadda H, Peres K, Foubert-Samier A, Dartigues JF, Helmer C (2016) Trends in dementia incidence: Evolution over a 10-year period in France. Alzheimers Dement 12, 272-280.
[69] Winblad B, Palmer K, Kivipelto M, Jelic V, Fratiglioni L, Wahlund LO, Nordberg A, Bäckman L, Albert M, Almkvist O, Arai H, Basun H, Blennow K, de Leon M, DeCarli C, Erkinjuntti T, Giacobini E, Graff C, Hardy J, Jack C, Jorm A, Ritchie K, van Duijn C, Visser P, Petersen RC (2004) Mild cognitive impairment-beyond controversies, towards a consensus: Report of the International Working Group on Mild Cognitive Impairment. J Intern Med 256, 240-246.

[70] Petersen R (2004) Mild cognitive impairment as a diagnostic entity. J Intern Med 256, 183-194.

[71] Petersen RC, Smith GE, Waring SC, Ivnik RJ, Tangalos EG, Kokmen E (1999) Mild cognitive impairment: Clinical characterization and outcome. Arch Neurol 56, 303-308.

[72] Petersen RC, Caracciolo B, Brayne C, Gauthier S, Jelic V, Fratiglioni L (2014) Mild cognitive impairment: A concept in evolution. J Intern Med 275, 214-228.

[73] Atri A (2019) The Alzheimer's disease clinical spectrum: Diagnosis and management. Med Clin 103, 263-293.

[74] Pavasini R, Guralnik J, Brown JC, Di Bari M, Cesari M, Landi F, Vaes B, Legrand D, Verghese J, Wang C (2016) Short physical performance battery and all-cause mortality: Systematic review and meta-analysis. BMC Med 14, 215.

[75] Fowler NR, Head KJ, Perkins AJ, Gao S, Callahan CM, Bakas T, Suarez SD, Boustani MA (2020) Examining the benefits and harms of Alzheimer's disease screening for family members of older adults: Study protocol for a randomized controlled trial. Trials 21, 202.

[76] Dos Santos PM, O'Caoimh R, Svendrovski A, Casanovas C, Pernas FO, Illario M, Molloy W, Paul C (2019) The RAPid COmmunity COGnitive screening Programme (RAPCOG): Developing the Portuguese version of the quick mild cognitive impairment (Qmci-P) screen as part of the EIP on AHA twinning scheme. Transl Med UniSa 19, 82.

[77] Perin S, Buckley RF, Pase MP, Yassi N, Lavale A, Wilson PH, Schembri A, Maruff P, Lim YY (2020) Unsupervised assessment of cognition in the Healthy Brain Project: Implications for web-based registries of individuals at risk for Alzheimer's disease. Alzheimers Dement (N Y) 6, e12043.

[78] Farias ST, Mungas D, Reed BR, Harvey D, DeCarli C (2009) Progression of mild cognitive impairment to dementia in clinic-vs community-based cohorts. Arch Neurol 66, 11511157.

[79] Montine TJ, Cholerton BA, Corrada MM, Edland SD, Flanagan ME, Hemmy LS, Kawas CH, White LR (2019) Concepts for brain aging: Resistance, resilience, reserve, and compensation. Alzheimers Res Ther 11, 22.

[80] White LR, Edland SD, Hemmy LS, Montine KS, Zarow C, Sonnen JA, Uyehara-Lock JH, Gelber RP, Ross GW, Petrovitch H, Masaki KH, Lim KO, Launer LJ, Montine TJ (2016) Neuropathologic comorbidity and cognitive impairment in the Nun and Honolulu-Asia Aging Studies. Neurology 86, 1000-1008.

[81] Roberts R, Knopman DS (2013) Classification and epidemiology of MCI. Clin Geriatr Med 29, 753-772.

[82] Janelidze S, Stomrud E, Smith R, Palmqvist S, Mattsson N, Airey DC, Proctor NK, Chai X, Shcherbinin S, Sims JR, Triana-Baltzer G, Theunis C, Slemmon R, Mercken M, Kolb H, Dage JL, Hansson O (2020) Cerebrospinal fluid p-tau 217 performs better than p-tau181 as a biomarker of Alzheimer's disease. Nat Commun 11, 1683. 